\title{
Regulation and role of suppressor of cytokine signaling-3 in hypothalamic $4 B$ cells
}

\author{
Kazunori Kageyama, Komaki Hanada, Yasumasa Iwasaki ${ }^{1}$ and Toshihiro Suda \\ Department of Endocrinology and Metabolism, Hirosaki University Graduate School of Medicine, 5 Zaifu-cho, Hirosaki, Aomori 036-8562, Japan \\ ${ }^{1}$ Department of Endocrinology, Metabolism and Nephrology, Kochi Medical School, Kochi University, Oko-cho, Kohasu, Nankoku 783-8505, Japan \\ (Correspondence should be addressed to K Kageyama; Email: kkageyama@hkg.odn.ne.jp)
}

\begin{abstract}
Corticotropin-releasing factor (CRF) plays a central role in regulating stress responses. In the hypothalamic paraventricular nucleus (PVN), CRF, produced in response to stress, stimulates the release of $\mathrm{ACTH}$ from the anterior pituitary. ACTH then stimulates the release of glucocorticoids from the adrenal glands; circulating glucocorticoids are critical for recovery from stress conditions. Cytokines are also implicated in the regulation of CRF expression. Among them, interleukin (IL)-6 plays a role in the regulation of CRF. Factors other than glucocorticoids are likely to be involved in limiting the stimulation of CRF during stress. Suppressor of cytokine signaling (SOCS)-3 acts as a potent negative regulator of cytokine signaling. Little is known about the ability of the inhibitory signaling pathways to limit activation of the CRF gene in parvocellular PVN neurons.
\end{abstract}

Hypothalamic 4B cells are useful for exploring the mechanisms, because these cells show characteristics of the parvocellular neurons of the PVN. In the present study, we examined whether SOCS-3 is regulated by IL-6 and cAMP in hypothalamic 4B cells. We also explored the involvement of SOCS-3 in the regulation of CRF gene expression. SOCS-3 was found to be regulated by IL- 6 and via the cAMP/protein kinase A pathway in the hypothalamic cells. SOCS-3 knockdown increased IL-6- or forskolin-induced CRF gene transcription and mRNA levels. Therefore, SOCS-3, induced by a cAMP stimulant and IL-6, would be involved in the negative regulation of CRF gene expression in hypothalamic cells.

Journal of Endocrinology (2009) 201, 369-376

\section{Introduction}

Corticotropin-releasing factor (CRF), a 41-amino acid polypeptide isolated originally from the ovine hypothalamus, plays a central role in regulating stress responses (Vale et al. 1981, Suda et al. 2004). CRF coordinates neuroendocrine, behavioral, autonomic, and immune responses, and controls the hypothalamic-pituitary-adrenal (HPA) axis during stressful periods. In the hypothalamic paraventricular nucleus (PVN) of the brain, CRF, produced in response to stress, stimulates the release of ACTH via CRF receptor type $1\left(\mathrm{CRF}_{1}\right.$ receptor) from the anterior pituitary (AP; Vale et al. 1981, Moriyama et al. 2005). ACTH then stimulates the release of glucocorticoids from the adrenal glands (Whitnall 1993). Circulating glucocorticoids are critical for recovery from stress conditions, because they inhibit hypothalamic PVN production of CRF and pituitary production of $\mathrm{ACTH}$, thereby ensuring that serum levels of glucocorticoids are appropriate to the stress experienced (Whitnall 1993).

Stimulation of the protein kinase A (PKA) pathway increases expression of CRF in the hypothalamus (Suda et al. 1985). Other studies also indicate that cAMP-dependent signaling activates CRF gene expression. A functional cAMPresponse element (CRE) on the $5^{\prime}$-promoter region is important for increasing CRF gene expression (Seasholtz et al. 1988, Spengler et al. 1992). In addition, King et al. (2002) demonstrated a second response element by cAMP between bps -125 and -118 , a caudal-type homeobox response element in the CRF promoter. Therefore, both the CRE and the caudal-type homeobox response element on the CRF promoter contribute to a cAMP-associated increase in the CRF gene (Cheng et al. 2000, King et al. 2002). In addition, pituitary adenylate cyclase-activating polypeptide (PACAP) induces cAMP, and stimulates the CRF gene via the cAMP/ PKA signaling pathway (Agarwal et al. 2005).

Cytokines are also implicated in the regulation of CRF expression. Among them, interleukin (IL)-6 is an important mediator of the interaction between the neuroendocrine and immune systems, and plays a role in the regulation of CRF. For example, IL-6 increases CRF gene expression and secretion in the hypothalamus (Navarra et al. 1991, Vallieres \& Rivest 1999). IL-6 stimulates the HPA axis (Venihaki et al. 2001), leading to an increase in glucocorticoid levels, which in turn suppresses IL-6 production (Karalis et al. 1997, Turnbull \& Rivier 1999). 
It has been suggested that factors other than glucocorticoids are also involved in limiting the stimulation of CRF during stress (Liu et al. 2006). Suppressor of cytokine signaling (SOCS)-3 acts as a potent negative regulator of cytokine signaling (Krebs \& Hilton 2000), and is known to suppress cytokine-induced proopiomelanocortin (POMC) gene transcription and ACTH secretion in corticotrophs (Auernhammer et al. 1999). IL-6 stimulates the Janus kinase/ signal transducers and activators of transcription (JAK/ STAT) signaling pathway, while IL-6-induced SOCS-3 acts as a negative regulator and inhibits STAT phosphorylation by JAK at the receptor complex (Ram \& Waxman 1999, Schmitz et al. 2000).

Little is known about the ability of the inhibitory signaling pathways to limit activation of the CRF gene in parvocellular PVN neurons. Hypothalamic 4B cells are useful for exploring the mechanisms, because these cells express CRF and vasopressin along with $\mathrm{CRF}_{1}$ and glucocorticoid receptors, and show characteristics of the parvocellular neurons of the PVN. In 4B cells transfected with a CRF promoter-luciferase construct, forskolin increased the activity of the CRF promoter in parallel with an increase in intracellular cAMP (Nikodemova et al. 2003).

In the present study, we examined whether SOCS-3 is regulated by IL-6 and cAMP in hypothalamic 4B cells. We also explored the involvement of SOCS-3 in the regulation of CRF gene expression in hypothalamic $4 \mathrm{~B}$ cells.

\section{Materials and Methods}

\section{Materials}

Forskolin was purchased from Calbiochem (San Diego, CA, USA). Rat IL-6 was purchased from PeproTech (London, UK). H89 was purchased from Seikagaku Corporation (Tokyo, Japan), and JAK Inhibitor I was purchased from Calbiochem.

\section{Cell culture}

4B cells were incubated in DMEM, supplemented with 10\% fetal bovine serum (FBS), $100 \mathrm{mg} / \mathrm{ml}$ streptomycin, and $100 \mathrm{U} / \mathrm{ml}$ penicillin at $37^{\circ} \mathrm{C}$, in a humidified atmosphere of $5 \% \mathrm{CO}_{2}$ and $95 \%$ air. Cells were plated at $10^{4} \mathrm{cells} / \mathrm{cm}^{2}$ for 4 days before each experiment and the medium was changed every $48 \mathrm{~h}$. One day before each experiment, cells were washed and then serum-starved overnight in DMEM supplemented with $0 \cdot 2 \% \mathrm{BSA}$.

\section{RNA extraction}

Cellular total RNA was extracted using the RNeasy Mini Kit (Qiagen), according to the manufacturer's protocol. cDNAs were then synthesized from total RNA $(0.5 \mu \mathrm{g})$ using random hexamers as primers with the SuperScript
First Strand Synthesis System for reverse transcriptase-PCR (RT-PCR; Invitrogen Corp.), according to the manufacturer's instructions.

\section{Real-time RT-PCR}

The resulting cDNAs were subjected to real-time PCR as follows. The expression level of rat SOCS-3 mRNA was evaluated using quantitative real-time PCR based on specific sets of primers and probes (Assays-on-Demand Gene Expression Products, Applied Biosystems, Foster City, CA, USA). The expression level of rat CRF mRNA was evaluated using quantitative real-time PCR based on the following specific sets of primers and probes: CRF-F (5'-TGGATCTCACCTTCCACCTTCTG-3'); CRF-R (5'-CCGATAATCTCCATCAGTTTCCTG-3'); probe (5'-FAM-GCCAGGGCAGAGCAGTTAGC-TAMRA-3'). $\beta 2$-microglobulin (B2MG), which was not changed by any treatments, was used as a housekeeping gene to normalize values. Each reaction consisted of $1 \times$ TaqMan Universal PCR Master Mix (Applied Biosystems), 1× Assayson-Demand Gene Expression Product (Rn00585674 s1 for rat SOCS-3; Rn00560865 $\mathrm{m} 1$ for rat B2MG) or a set of CRF primers and probes, and $2 \mu \mathrm{l}$ cDNA in a total volume of $50 \mu \mathrm{l}$, using the following parameters with an ABI PRISM 7000 Sequence Detection System (Applied Biosystems): $95{ }^{\circ} \mathrm{C}$ for $10 \mathrm{~min}, 40$ cycles at $95^{\circ} \mathrm{C}$ for $15 \mathrm{~s}$, and $60^{\circ} \mathrm{C}$ for $1 \mathrm{~min}$. Data were collected and recorded by ABI PRISM 7000 SDS Software (Applied Biosystems) and expressed as a function of the threshold cycle $\left(C_{\mathrm{t}}\right)$. Using diluted samples, the amplification efficacies for each gene of interest and the housekeeping gene amplimers were found to be identical.

\section{Relative quantitative gene expression}

Relative quantitative gene expression was calculated by the $2^{-\Delta \Delta C_{\mathrm{t}}}$ method (Livak \& Schmittgen 2001). In brief, for each sample assayed, the $C_{\mathrm{t}}$ for the reactions amplifying the gene of interest (rat SOCS-3) and a housekeeping gene (rat B2MG) was determined. The $C_{t}$ for the gene of interest of each sample was corrected by subtracting the $C_{\mathrm{t}}$ for the housekeeping gene $\left(\Delta C_{\mathrm{t}}\right)$. Untreated controls were chosen as reference samples, and the $\Delta C_{\mathrm{t}}$ for all experimental samples was reduced by the average $\Delta C_{\mathrm{t}}$ for the control samples $\left(\Delta \Delta C_{\mathrm{t}}\right)$. Finally, the abundance of the experimental mRNA relative to that of the control mRNA was calculated with use of the formula $2^{-\Delta \Delta C_{\mathrm{t}}}$.

\section{Western-blot analysis}

After each treatment, cells were washed twice with PBS and lysed with Laemmli sample buffer. Cell debris was pelleted by centrifugation, and the supernatant was recovered. Samples were boiled and subjected to electrophoresis on a gradient (4-20\%) polyacrylamide gel. Proteins were transferred to a PVDF membrane (Daiichi Kagaku, Tokyo, Japan). 
After blocking by Detector Block blocking buffer (Kirkegaard \& Perry Laboratories, Inc., Gaithersburg, MD, USA), the membrane was incubated for $1 \mathrm{~h}$ with a rabbit anti-CRE-binding protein (CREB) antibody (Cell Signaling Technology, Beverly, MA, USA), anti-phosphorylated (p)-CREB antibody (Cell Signaling Technology), antiSTAT3 antibody (Cell Signaling Technology), anti-p-STAT3 antibody (Cell Signaling Technology), anti-SOCS-3 antibody (Santa Cruz Biotechnology, Santa Cruz, CA, USA), or antiactin antibody (Santa Cruz Biotechnology), washed with PBS containing $0 \cdot 05 \%$ Tween 20 , and incubated with HRP-labeled anti-rabbit IgG (Daiichi Kagaku). Detection was performed using a chemiluminescent substrate Super-signal WestPico (Pierce Chemical Co., Rockford, IL, USA), and the membrane was exposed to BioMax film (Eastman Kodak Co.), and followed by quantitative analysis using the NIH image software 1.61. The results are expressed as corrected arbitrary units.

\section{Constructs and transfection}

A 1077 bp restriction fragment containing the human CRF promoter $(-907$ to +170 relative to the proximal transcription start point) was obtained by PCR. The PCR products were then confirmed by sequencing. This DNA fragment was used to produce the CRF promoter-driven luciferase reporter construct, CRF-907luc, by a two-step cloning method. First, the DNA fragment was cloned into pGEM-T Easy vector (Promega Corp.), then digested with Kpn I and Hind III, and subcloned into Kpn I- and Hind III-cloning sites of the pA3-Luc plasmid. SOCS-3-2757luc containing the promoter region -2757 to +929 of the murine SOCS-3 gene fused to the luciferase-encoding sequence was provided by Dr S Melmed (Sinai Research Center, Los Angeles, CA, USA). SOCS-3-159luc and SOCS-3-107luc were generated by Dr C Ehlting (Heinrich-Heine University, Dusseldorf, Germany).

For the luciferase activity assay, cells were placed in 12-well (22-mm diameter) culture dishes at $60 \%$ confluency. The following day, the cells were transiently transfected using the FuGENE 6 Transfection Reagent Kit (Roche Diagnostics) in accordance with the manufacturer's instructions. A FuGENE to DNA ratio of $3 \mu \mathrm{l}: 1 \mu \mathrm{g}$ was used. The total amount of DNA in each well was $0.5 \mu \mathrm{g}$. The culture medium was then replaced with DMEM supplemented with 10\% FBS. Three days after transfection, the cells were washed and serumstarved overnight in DMEM supplemented with $0 \cdot 2 \%$ BSA. Each experiment was then performed.

\section{Luciferase activity}

A luciferase assay was performed according to the manufacturer's protocol. At the end of each experiment, cells were washed twice with PBS without $\mathrm{Ca}^{2+}$ and $\mathrm{Mg}^{2+}$, harvested with PicaGene lysis buffer (Toyo Inki, Tokyo, Japan), and centrifuged at $9660 \mathrm{~g}$ for $2 \mathrm{~min}$. Twenty microliters of each supernatant was used for the luciferase assay.
The reactions were initiated by the injection of $100 \mathrm{ml}$ of luciferin solution, PicaGene buffer. Light output was measured for $20 \mathrm{~s}$ at room temperature using a luminometer (Berthold Lumat LB9501, Postfach, Germany). The activity of $\beta$-galactosidase was used as an internal control.

\section{$R N A$ interference experiments}

SOCS-3 and control siRNAs were designed and purchased from Ambion (Austin, TX, USA). The 4B cells were transfected with siRNA and siPORT NeoFX transfection reagent (Ambion) according to the manufacturer's protocol. The $4 \mathrm{~B}$ cells, seeded into 12 -well plates at a density of $2 \times 10^{4}$ cells/well, were incubated for $24 \mathrm{~h}$ in $1 \mathrm{ml}$ of culture medium containing siRNA for either control (siControl) or SOCS-3 (siSOCS-3). For the luciferase assay, after transfection the cells were re-transfected with CRF-promoter constructs, and then incubated with forskolin or IL-6. For a measurement of CRF mRNA levels, the cells were incubated with $1 \mathrm{mM}$ forskolin or IL-6 following transfection. The expression of CRF and B2MG mRNA was examined by quantitative RT-PCR.

\section{Statistical analysis}

Each value is expressed as mean \pm S.E.M. Statistical analyses of the data were performed using either unpaired $t$-test or ANOVA, followed by the Bonferroni/Dunn post hoc test. The level of statistical significance was set at $P<0 \cdot 05$.

\section{Results}

\section{Effects of IL-6 or forskolin on SOCS-3 levels in $4 B$ cells}

We examined time-dependent and dose-dependent changes in SOCS-3 mRNA levels by the stimulation of IL-6. The time-course study showed that IL-6 significantly increased SOCS-3 mRNA levels (Fig. 1A-1). The maximal effect of IL-6 $(100 \mathrm{ng} / \mathrm{ml})$ occurred $24 \mathrm{~h}$ after treatment, with an approximate fourfold increase in SOCS-3 mRNA levels. The dose-response study showed that IL-6 induced significant stimulatory effects at both 10 and $100 \mathrm{ng} / \mathrm{ml}$ (Fig. 1A-2). We also examined time-dependent and dose-dependent changes in SOCS-3 mRNA levels by the stimulation of forskolin. The time-course study showed that the most significant effect of forskolin $(10 \mu \mathrm{M})$ was observed at $2 \mathrm{~h}$, with approximately a twofold increase compared with the basal level (Fig. 1B-1). The dose-response study showed that forskolin induced a significant stimulatory effect at $10 \mu \mathrm{M}$ in $4 \mathrm{~B}$ cells (Fig. 1B-2).

Forskolin stimulates adenylate cyclase, and then intracellular cAMP production. We examined cAMP-dependent changes in SOCS-3 protein levels through stimulation by forskolin. The time-course study showed that the significant effect of forskolin $(10 \mu \mathrm{M})$ was observed at 6 and $24 \mathrm{~h}$, with an $\sim 2.5$-fold increase compared with the basal level 

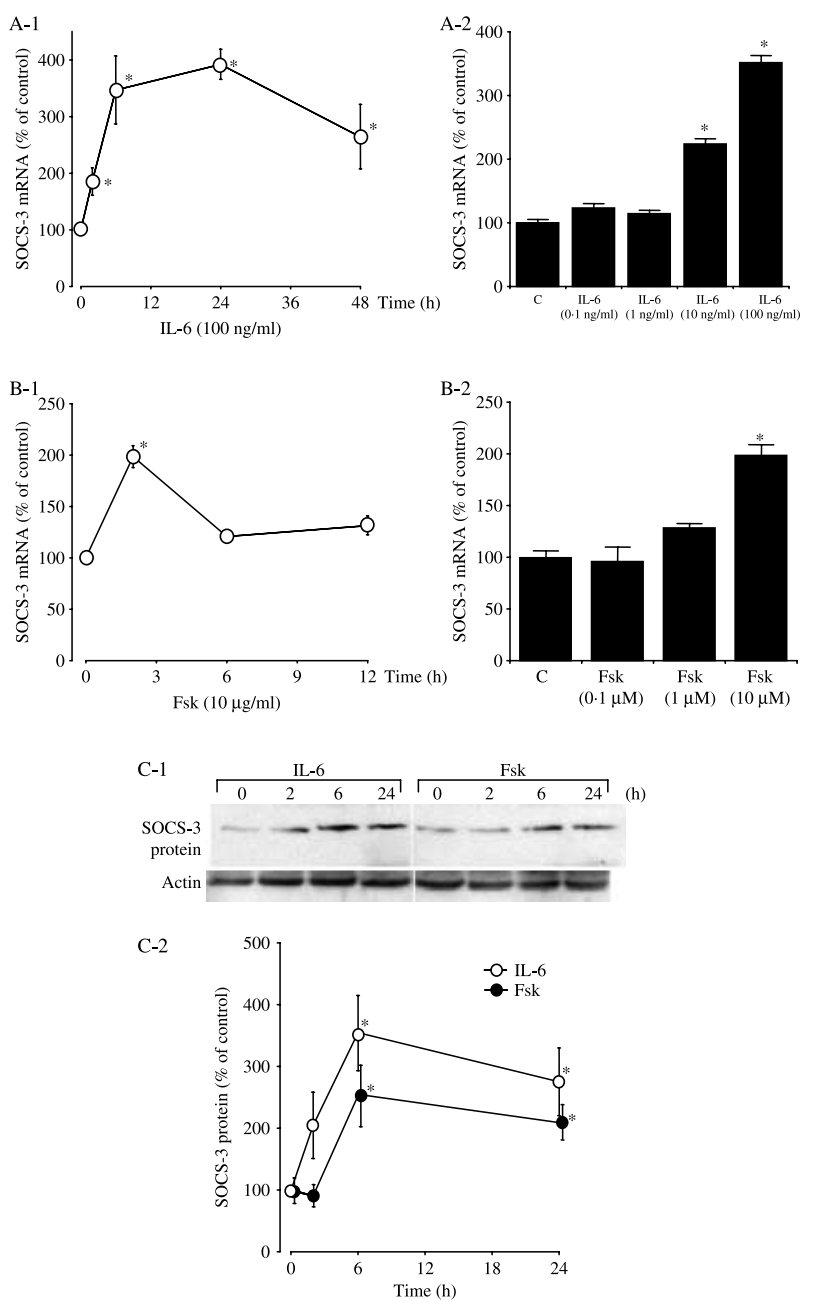

Figure 1 Effects of IL-6 and forskolin on SOCS-3 levels in 4B cells. Control cells treated with medium alone are indicated as (C). Experiments were conducted in triplicate, and the means of three independent experiments are shown. Statistical analyses were performed using one-way ANOVA, followed by post hoc tests. ${ }^{*} P<0 \cdot 05$ (compared with control (C)). (A-1) Time-dependent changes in IL-6-induced SOCS-3 mRNA levels. Cells were incubated with medium containing $100 \mathrm{ng} / \mathrm{ml} \mathrm{IL-6}$ for the durations shown. (A-2) Dose-dependent changes in IL-6-induced SOCS-3 mRNA levels. Cells were incubated for $24 \mathrm{~h}$ with medium containing $0 \cdot 1-100 \mathrm{ng} / \mathrm{ml} \mathrm{IL-6.} \mathrm{(B-1)} \mathrm{Time-dependent}$ changes in forskolin-induced SOCS-3 mRNA levels. Cells were incubated with medium containing $10 \mu \mathrm{M}$ forskolin (Fsk) for the durations shown. (B-2) Dose-dependent changes in forskolininduced SOCS-3 mRNA levels. Cells were incubated for $2 \mathrm{~h}$ with medium containing $0 \cdot 1-10 \mu \mathrm{M}$ forskolin (Fsk). (C-1) Effects of forskolin or IL-6 on SOCS-3 protein in 4B cells. Cells were incubated with medium containing $10 \mu \mathrm{M}$ forskolin (Fsk) or $100 \mathrm{ng} / \mathrm{ml} \mathrm{IL-} 6$ for the durations shown. A representative image of western blot for SOCS-3 and actin proteins in 4B cells. (C-2) Effects of forskolin or IL-6 on SOCS-3 protein in 4B cells. Experiments were conducted in triplicate, and the means of three independent experiments are shown. Statistical analyses were performed using two-way ANOVA, followed by post hoc tests. $* P<0 \cdot 05$ (compared with each control).
(Fig. 1C-1 and C-2). We also examined a time-dependent change in SOCS-3 protein levels by stimulation with IL-6. The time-course study showed that IL-6 significantly increased SOCS-3 protein levels. The maximal effect of IL-6 $(100 \mathrm{ng} / \mathrm{ml})$ occurred $6 \mathrm{~h}$ after treatment, with an approximate $3 \cdot 5$-fold increase in SOCS-3 protein levels (Fig. 1C-1 and C-2).

\section{Effects of JAK and PKA inhibitors on SOCS-3 $m R N A$ levels}

To determine whether a JAK pathway is involved in IL-6-induced SOCS-3 mRNA levels, 4B cells were incubated with a potent JAK inhibitor. SOCS-3 mRNA levels were not affected by treatment with $1 \mu \mathrm{M}$ JAK Inhibitor I. However, the stimulatory effects of IL-6 on SOCS-3 mRNA levels were completely inhibited by treatment with $1 \mu \mathrm{M}$ JAK Inhibitor I (Fig. 2A).

To determine whether the PKA pathway is involved in forskolin-induced SOCS-3 mRNA levels, 4B cells were incubated with $1 \mu \mathrm{M} \mathrm{H89}$, a potent and selective PKA inhibitor $\left(\mathrm{IC}_{50}=48 \mathrm{nM}\right)$. SOCS-3 mRNA levels were not affected by treatment with $1 \mu \mathrm{M} \mathrm{H89}$; however, the stimulatory effects of forskolin on SOCS-3 mRNA levels were completely inhibited by treatment with $1 \mu \mathrm{M}$ H89 (Fig. 2B).

Effects of forskolin or IL-6 on CREB or STAT3 phosphorylation in $4 B$ cells

We studied $4 \mathrm{~B}$ cells to determine whether treatment with IL-6 had an effect on STAT3 phosphorylation. Incubation with $100 \mathrm{ng} / \mathrm{ml}$ of IL-6 increased STAT3 phosphorylation from between $5 \mathrm{~min}$ and $2 \mathrm{~h}$ after the addition (Fig. 3A).
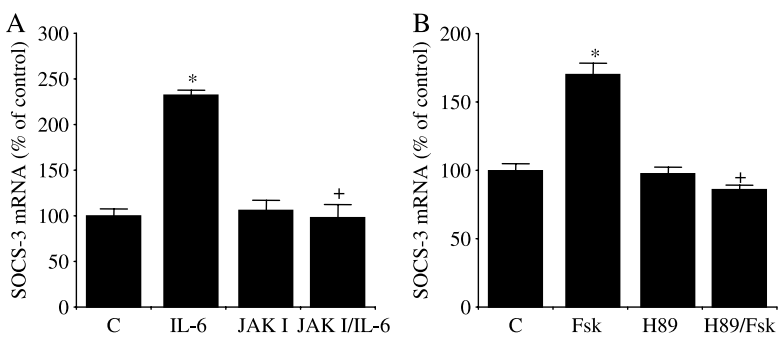

Figure 2 Effects of JAK and PKA inhibitors on SOCS-3 mRNA levels. Control cells treated with medium alone are indicated as (C). Experiments were conducted in triplicate, and the means of three independent experiments are shown. Statistical analyses were performed using one-way ANOVA, followed by post hoc tests. ${ }^{*} P<0 \cdot 05$ (compared with control $(\mathrm{C})$ ). ${ }^{+} P<0.05$ (compared with forskolin (Fsk)). (A) Effects of JAK inhibitor I on IL-6-stimulated SOCS-3 mRNA levels. Cells were pre-incubated for $30 \mathrm{~min}$ with medium containing $1 \mu \mathrm{M}$ JAK inhibitor I (JAK I) or vehicle, and then incubated for $6 \mathrm{~h}$ with medium containing $100 \mathrm{ng} / \mathrm{ml} \mathrm{IL-6}$ or vehicle. (B) Effects of $\mathrm{H} 89$ on forskolin-stimulated SOCS-3 mRNA levels. Cells were pre-incubated for $30 \mathrm{~min}$ with medium containing $1 \mu \mathrm{M} \mathrm{H} 89$ or vehicle, and then incubated for $2 \mathrm{~h}$ with medium containing $10 \mu \mathrm{M}$ forskolin (Fsk) or vehicle. 
A
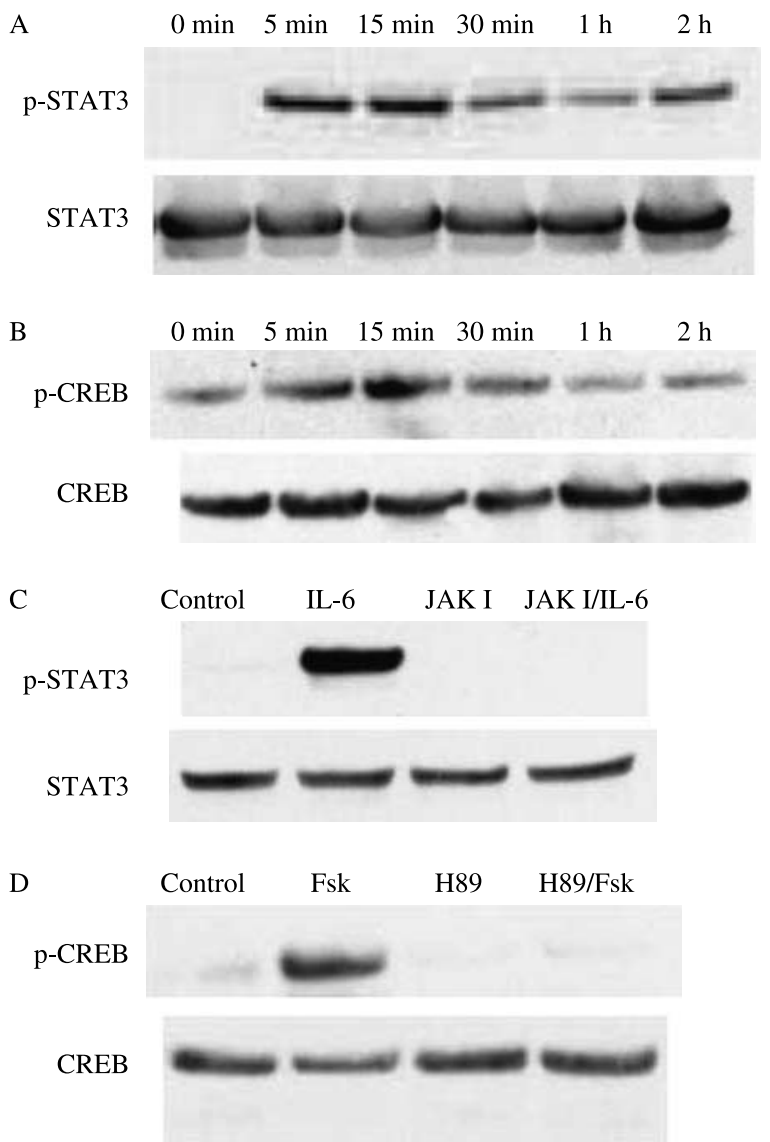

Figure 3 Effects of forskolin or IL-6 on CREB or STAT3 phosphorylation in $4 \mathrm{~B}$ cells. Independent experiments were repeated three times, and a representative blot is shown. (A) Time-dependent changes in IL-6-induced STAT3 phosphorylation. Cells were incubated with medium containing $100 \mathrm{ng} / \mathrm{ml} \mathrm{IL-6}$ for the durations shown. (B) Time-dependent changes in forskolin-induced CREB phosphorylation. Cells were incubated with medium containing $10 \mu \mathrm{M}$ forskolin for the durations shown. (C) Effects of JAK inhibitor I on IL-6-stimulated STAT3 phosphorylation. Cells were preincubated for 30 min with medium containing $1 \mu \mathrm{M}$ JAK inhibitor I (JAK I) or vehicle, and then incubated for $15 \mathrm{~min}$ with medium containing $100 \mathrm{ng} / \mathrm{ml} \mathrm{IL-6}$ or vehicle. (D) Effects of H89 on forskolin-stimulated CREB phosphorylation. Cells were pre-incubated for 30 min with medium containing $1 \mu \mathrm{M} \mathrm{H} 89$ or vehicle, and then incubated for 15 min with medium containing $10 \mu \mathrm{M}$ forskolin (Fsk) or vehicle.

We then examined 4B cells to determine whether treatment with forskolin affected CREB phosphorylation. Incubation with $10 \mu \mathrm{M}$ of forskolin increased CREB phosphorylation at 5 and $15 \mathrm{~min}$ after the addition (Fig. 3B).

To determine whether the JAK pathway was involved in IL-6-induced phosphorylation of STAT3, 4B cells were pre-incubated for $30 \mathrm{~min}$ with JAK I inhibitor, prior to the addition of IL-6. JAK I inhibitor inhibited an IL-6-mediated increase in STAT3 phosphorylation (Fig. 3C). To determine whether PKA was involved in forskolin-induced phosphorylation of CREB, 4B cells were pre-incubated for $30 \mathrm{~min}$ with $\mathrm{H} 89$ prior to the addition of forskolin. H89 inhibited a forskolin-mediated increase in CREB phosphorylation (Fig. 3D).

\section{Effects of IL-6 on SOCS-3 5'-promoter activity in $4 B$ cells}

We examined time-dependent changes in SOCS-3 5 -promoter activity. The time-course study showed an increasing effect of IL-6 in a time-dependent manner (Fig. 4). To determine whether a proximal part of the SOCS-3 $5^{\prime}$ promoter was involved in the regulation of the IL-6 activity, 4B cells transfected with a series of promoter deletion constructs, such as SOCS-3-2757luc, SOCS-3159luc, and SOCS-3-107luc, were stimulated with IL-6. 4B cells transfected with SOCS-3-2757luc showed similar potent SOCS-3-promoter activity to the cells transfected with SOCS-3-159luc. Cells transfected with SOCS-3107luc showed enhanced activity compared with the longer constructs.

Effects of SOCS-3 on the regulation of CRF gene in $4 B$ cells

We then examined the functional role of SOCS-3 in $4 \mathrm{~B}$ cells, since SOCS-3 might be involved in the regulation of CRF $5^{\prime}{ }_{-}$ promoter activity. SOCS-3 mRNA levels were reduced by $48 \%$ in cells transfected with siRNA against the SOCS-3 gene. SOCS-3 knockdown did not have any significant effect on basal CRF $5^{\prime}$-promoter activity compared with the control (Fig. 5A). However, there was a significant increase in forskolin- or IL-6-induced CRF $5^{\prime}$-promoter activity (Fig. 5B and C).

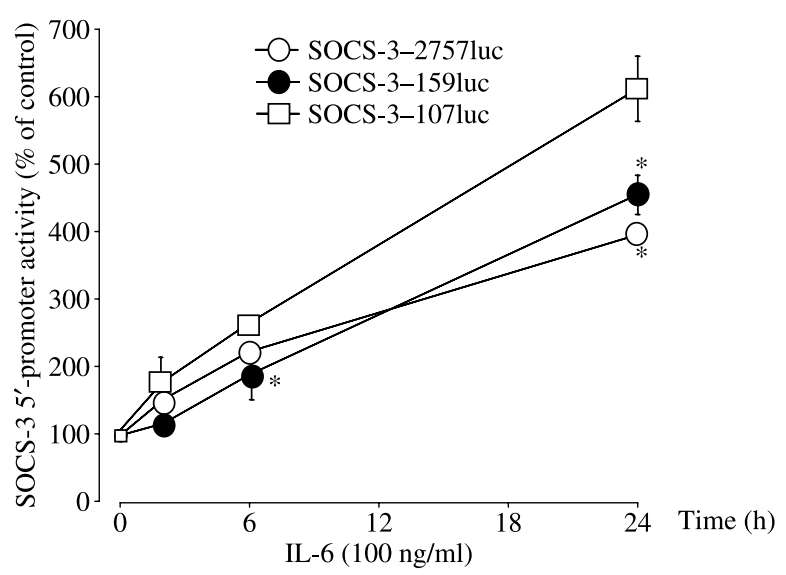

Figure 4 Effects of IL-6 on SOCS-3 5'-promoter activity in 4B cells. Cells transfected with a full-length (SOCS-3-2757luc) or shorter (SOCS-3-159luc or SOCS-3-107luc) promoter constructs were incubated with medium containing $100 \mathrm{ng} / \mathrm{ml} \mathrm{IL-6}$ for the durations shown. Experiments were conducted in triplicate, and the means of three independent experiments are shown. Statistical analyses were performed using two-way ANOVA, followed by post hoc tests. ${ }^{*} P<0 \cdot 05$ (compared with SOCS-3-107luc). 

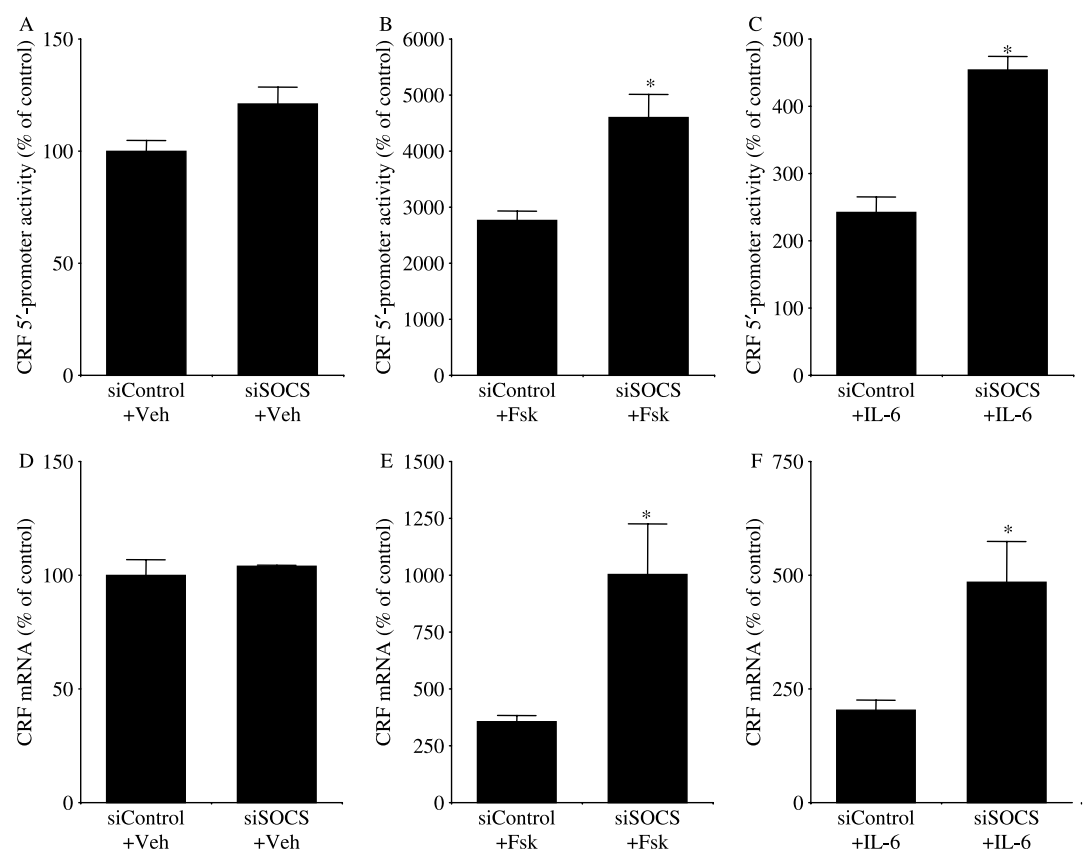

Figure 5 Effects of SOCS-3 on the regulation of CRF gene in $4 \mathrm{~B}$ cells. Experiments were conducted in triplicate, and the means of three independent experiments are shown. Statistical analyses were performed using unpaired $t$-test. ${ }^{*} P<0 \cdot 05$ (compared with control (siControl)). The $4 \mathrm{~B}$ cells, seeded into 12 -well plates at a density of $2 \times 10^{4}$ cells/well, were incubated for $24 \mathrm{~h}$ in $1 \mathrm{ml}$ of culture medium containing siRNA for either control (siControl) or SOCS (siSOCS). (A-C) Effects of SOCS-3 on the regulation of CRF 5'-promoter activity. After transfection, the cells were re-transfected with a CRF-promoter construct, and then incubated with vehicle (A), $10 \mu \mathrm{M}$ forskolin (Fsk) for $2 \mathrm{~h} \mathrm{(B),} \mathrm{or} 100 \mathrm{ng} / \mathrm{ml} \mathrm{IL-6} \mathrm{for} 24 \mathrm{~h}(\mathrm{C})$. (D and E) Effects of SOCS-3 on the regulation of CRF mRNA levels. The cells were incubated with vehicle (D), $10 \mu \mathrm{M}$ forskolin (Fsk) for $2 \mathrm{~h} \mathrm{(E),} \mathrm{or} 100 \mathrm{ng} / \mathrm{ml} \mathrm{IL-6}$ for $24 \mathrm{~h}$ (F).

We next examined the expression levels of CRF mRNA by quantitative RT-PCR. SOCS-3 knockdown did not have any significant effect on basal CRF mRNA levels compared with the control (Fig. 5D). CRF mRNA levels were induced by incubation with forskolin or IL-6 (Fig. 5E and F). SOCS-3 knockdown significantly increased forskolin- or IL-6-induced CRF mRNA levels compared with the control (Fig. 5E and F).

\section{Discussion}

SOCS-3 is known to be a potent negative regulator of cytokine signaling (Krebs \& Hilton 2000), and is induced by IL-6-type cytokines in corticotrophs (Chesnokova \& Melmed 2002). In this study, we found that SOCS-3 was regulated by IL-6 in hypothalamic cells. Thus, it is suggested that SOCS-3 would be regulated by IL-6 both in the hypothalamus and in the pituitary corticotrophs. In fact, in the hypothalamic cells, IL-6-induced STAT3 tyrosine phosphorylation depended on the JAK pathway. IL-6-induced SOCS-3 mRNA levels were also regulated via the JAK pathway. Therefore, cytokine-induced expression of SOCS-3 molecules would be important for the negative regulatory control of STAT-dependent cytokine signaling through the JAK/STAT cascade. STAT activation would be critical for the activation of SOCS-3 gene expression. Furthermore, promoter analysis in AtT-20 has shown that the proximal STAT3-response element and GC-rich element, -107 to $-48 \mathrm{bp}$ on the $5^{\prime}$-upstream region of the POMC promoter, are implicated for its transcription (Ehlting et al. 2005). In addition, our data suggest that some inhibitory elements might exist on the region between -159 and $-107 \mathrm{bp}$ of the promoter, because cells transfected with SOCS-3-107luc showed enhanced activity compared with the longer constructs.

We also found that SOCS-3 was regulated via the cAMP/PKA pathway in the hypothalamic cells. Generally, stimulation of $\mathrm{G}$-protein-coupled receptors produces intracellular cAMP, which then activates the PKA pathway. In 4B cells, stimulation of the adenylate cyclase pathway by forskolin induces an accumulation of intracellular cAMP and activation of the PKA pathway (Kasckow et al. 2003, Nikodemova et al. 2003). Activation of this pathway leads to the binding of CREB to the CRE on the CRF promoter (Cheng et al. 2000). Bousquet et al. (2001) reported that activation of the cAMP/PKA pathway is involved in the regulation of SOCS-3 in AtT-20 cells. In our study, forskolin-induced CREB 
phosphorylation depended on the PKA pathway in the hypothalamic cells. Forskolin-induced SOCS-3 mRNA levels were also regulated via the PKA pathway. Bousquet et al. (2001) reported that CREB transduces cAMP-mediated induction of c-fos and JunB, and that multiple cAMPresponsive DNA-binding elements or CRE/AP-1 sites would be present on the SOCS-3 promoter. c-fos and JunB bound to an AP-1 site were identified as potential mediators of cAMP-induced SOCS-3-promoter activity. Stimulation with forskolin was less effective at inducing both SOCS-3 mRNA and protein levels than with IL-6. We previously found that an interaction between CAMP-PKA and IL-6 pathways stimulates the CRF gene in $4 \mathrm{~B}$ cells (Kageyama et al. 2007). However, such an interaction was not observed to stimulate SOCS-3, because IL-6- and forskolin-induced SOCS-3 mRNA levels were not blocked by a PKA inhibitor and a JAK inhibitor respectively (data not shown). Different signaling pathways might cause differential potencies between cAMP and IL-6.

In this study, SOCS-3 was regulated in the hypothalamic cells, suggesting that SOCS-3 would be involved in the negative regulation of CRF gene expression. We previously found that PACAP stimulates CRF-promoter activity via the PKA pathway in 4B cells (Kageyama et al. 2007). The previous study also showed that CRF-promoter activity declines within $6 \mathrm{~h}$ of treatment with a cAMP stimulant, PACAP (Kageyama et al. 2007), further suggesting this effect of SOCS-3. Our present study demonstrated that SOCS-3 knockdown increased forskolin-induced CRF gene transcription and mRNA levels. These results may suggest that cAMP-induced SOCS-3 would regulate the HPA axis by suppression of CRF gene expression in the hypothalamus. IL-6 also stimulated CRF-promoter activity and SOCS-3 protein in 4B cells (Kageyama et al. 2007). SOCS-3 knockdown increased IL-6-induced CRF gene transcription and mRNA levels. However, CRF-promoter activity still gradually increased $24 \mathrm{~h}$ after incubation with IL-6 (Kageyama et al. 2007). Therefore, the extent of involvement of IL-6-induced SOCS-3 in suppressing the increased levels of CRF gene expression in the hypothalamus needs to be established.

Hypothalamic 4B cells have been useful for exploring the stress responses in the PVN, because they show characteristics of the parvocellular neurons of the PVN. While the basal expression levels of CRF mRNA were weak in $4 \mathrm{~B}$ cells, they were induced by forskolin and IL-6. We previously reported that the cAMP-dependent PKA pathway plays important roles in the activation of CRF neurons in vivo under physiological conditions (Itoi et al. 1996). IL-6 is required to prolong or maintain CRF expression during the later phases of inflammation in vivo (Venihaki et al. 2001). Therefore, the mechanisms regulating CRF gene expression would remain in $4 \mathrm{~B}$ cells, reflecting the hypothalamus in vivo.

In conclusion, this study demonstrated that SOCS-3 was regulated by IL- 6 and by the cAMP/PKA pathway in hypothalamic cells. SOCS-3 knockdown increased IL-6- or forskolin-induced CRF gene transcription and mRNA levels. Therefore, SOCS-3, induced by a cAMP stimulant and IL-6, would be involved in the negative regulation of CRF gene expression in the hypothalamic cells.

\section{Declaration of interest}

The authors declare that there is no conflict of interest that could be perceived as prejudicing the impartiality of the research reported.

\section{Funding}

This work was supported in part by Health and Labour Science Research Grants (Research on Measures for Intractable Diseases) from the Ministry of Health, Labour, and Welfare of Japan, and by a grant to T S from the Ministry of Education, Science, and Culture of Japan (No. 18591014).

\section{Acknowledgements}

We thank Dr J Kasckow for providing the 4B cells. We also thank Drs S Melmed and C Ehling for providing the SOCS-3 promoter-reporter gene constructs.

\section{References}

Agarwal A, Halvorson LM \& Legradi G 2005 Pituitary adenylate cyclaseactivating polypeptide (PACAP) mimics neuroendocrine and behavioral manifestations of stress: evidence for PKA-mediated expression of the corticotropin-releasing hormone (CRH) gene. Brain Research. Molecular Brain Research 138 45-57.

Auernhammer CJ, Bousquet C \& Melmed S 1999 Autoregulation of pituitary corticotroph SOCS-3 expression: characterization of the murine SOCS-3 promoter. PNAS 96 6964-6969.

Bousquet C, Chesnokova V, Kariagina A, Ferrand A \& Melmed S 2001 cAMP neuropeptide agonists induce pituitary suppressor of cytokine signaling-3: novel negative feedback mechanism for corticotroph cytokine action. Molecular Endocrinology 15 1880-1890.

Cheng YH, Nicholson RC, King B, Chan EC, Fitter JT \& Smith R 2000 Glucocorticoid stimulation of corticotropin-releasing hormone gene expression requires a cyclic adenosine $3^{\prime}, 5^{\prime}$-monophosphate regulatory element in human primary placental cytotrophoblast cells. Journal of Clinical Endocrinology and Metabolism 85 1937-1945.

Chesnokova V \& Melmed S 2002 Neuro-immuno-endocrine modulation of the hypothalamic-pituitary-adrenal (HPA) axis by gp130 signaling molecules. Endocrinology 143 1571-1574.

Ehlting C, Häussinger D \& Bode JG 2005 Sp3 is involved in the regulation of SOCS3 gene expression. Biochemical Journal 387 737-745.

Itoi K, Horiba N, Tozawa F, Sakai Y, Sakai K, Abe K, Demura H \& Suda T 1996 Major role of $3^{\prime}, 5^{\prime}$-cyclic adenosine monophosphate-dependent protein kinase A pathway in corticotropin-releasing factor gene expression in the rat hypothalamus in vivo. Endocrinology 137 2389-2396.

Kageyama K, Hanada K, Iwasaki Y, Sakihara S, Nigawara T, Kasckow J \& Suda T 2007 Pituitary adenylate cyclase-activating polypeptide stimulates corticotropin-releasing factor, vasopressin and interleukin-6 gene transcription in hypothalamic 4B cells. Journal of Endocrinology 195 199-211.

Karalis K, Muglia LJ, Bae D \& Hilderbrand JA 1997 CRH and the immune system. Journal of Neuroimmunology 72 131-136.

Kasckow J, Mulchahey JJ, Aguilera G, Pisarska M, Nikodemova M, Chen HC, Herman JP, Murphy EK, Liu Y, Rizvi TA et al. 2003 Corticotropin- 
releasing hormone (CRH) expression and protein kinase A mediated CRH receptor signalling in an immortalized hypothalamic cell line. Journal of Neuroendocrinology 15 521-529.

King BR, Smith R \& Nicholson RC 2002 Novel glucocorticoid and cAMP interactions on the $\mathrm{CRH}$ gene promoter. Molecular and Cellular Endocrinology 194 19-28.

Krebs DL \& Hilton DJ 2000 SOCS: physiological suppressors of cytokine signaling. Journal of Cell Science 113 2813-2819.

Liu Y, Kalintchenko N, Sassone-Corsi P \& Aguilera G 2006 Inhibition of corticotrophin-releasing hormone transcription by inducible cAMP-early repressor in the hypothalamic cell line, 4B. Journal of Neuroendocrinology 18 $42-49$.

Livak KJ \& Schmittgen TD 2001 Analysis of relative gene expression data using real-time quantitative PCR and the $2(-$ Delta Delta $C(\mathrm{t}))$ method. Methods 25 402-408.

Moriyama T, Kageyama K, Kasagi Y, Iwasaki Y, Nigawara T, Sakihara S \& Suda T 2005 Differential regulation of corticotropin-releasing factor receptor type 1 (CRF1 receptor) mRNA via protein kinase A and mitogen-activated protein kinase pathways in rat anterior pituitary cells. Molecular and Cellular Endocrinology 243 74-79.

Navarra P, Tsagarakis S, Faria MS, Rees LH, Besser GM \& Grossman AB 1991 Interleukins- 1 and -6 stimulate the release of corticotropin-releasing hormone-41 from rat hypothalamus in vitro via the eicosanoid cyclooxygenase pathway. Endocrinology 128 37-44.

Nikodemova M, Kasckow J, Liu H, Manganiello V \& Aguilera G 2003 Cyclic adenosine $3^{\prime}, 5^{\prime}$-monophosphate regulation of corticotropin-releasing hormone promoter activity in AtT-20 cells and in a transformed hypothalamic cell line. Endocrinology 144 1292-1300.

Ram PA \& Waxman DJ 1999 SOCS/CIS protein inhibition of growth hormone-stimulated STAT5 signaling by multiple mechanisms. Journal of Biological Chemistry 274 35553-35561.

Schmitz J, Weissenbach M, Haan S, Heinrich PC \& Schaper F 2000 SOCS3 exerts its inhibitory function on interleukin-6 signal transduction through the SHP2 recruitment site of gp130. Journal of Biological Chemistry 275 $12848-12856$.
Seasholtz AF, Thompson RC \& Douglass JO 1988 Identification of a cyclic adenosine monophosphate-responsive element in the rat corticotropinreleasing hormone gene. Molecular Endocrinology 2 1311-1319.

Spengler D, Rupprecht R, Van LP \& Holsboer F 1992 Identification and characterization of a $3^{\prime}, 5^{\prime}$-cyclic adenosine monophosphate-responsive element in the human corticotropin-releasing hormone gene promoter. Molecular Endocrinology 6 1931-1941.

Suda T, Yajima F, Tomori N, Demura H \& Shizume K 1985 In vitro study of immunoreactive corticotropin-releasing factor release from the rat hypothalamus. Life Sciences 37 1499-1505.

Suda T, Kageyama K, Sakihara S \& Nigawara T 2004 Physiological roles of urocortins, human homologues of fish urotensin 1, and their receptors. Peptides 25 1689-1701.

Turnbull AV \& Rivier CL 1999 Regulation of the hypothalamic-pituitaryadrenal axis by cytokines: actions and mechanisms of action. Physiological Reviews 79 1-71.

Vale W, Spiess J, Rivier C \& Rivier J 1981 Characterization of a 41 residue ovine hypothalamic peptide that stimulates secretion of corticotropin and beta-endorphin. Science 213 1394-1397.

Vallieres L \& Rivest S 1999 Interleukin-6 is a needed proinflammatory cytokine in the prolonged neural activity and transcriptional activation of corticotropin-releasing factor during endotoxemia. Endocrinology 140 3890-3903.

Venihaki M, Dikkes P, Carrigan A \& Karalis KP 2001 Corticotropin-releasing hormone regulates IL-6 expression during inflammation. Journal of Clinical Investigation 108 1159-1166.

Whitnall MH 1993 Regulation of the hypothalamic corticotropin-releasing hormone neurosecretory system. Progress in Neurobiology 40 573-629.

\section{Received in final form 24 February 2009 \\ Accepted 13 March 2009 \\ Made available online as an Accepted Preprint 16 March 2009}

